\title{
Language as a Tool for Effective Communication Management
}

\author{
M.G. Bhaskar, Sahana. B
}

\begin{abstract}
Language forms the significant aspect of both verbal and written communication. Language constitutes the basic and fundamental requirement to understand any organisation's management policies by its employees across the globe from different language origin. Particularly in today's competitive international business scenario, the dynamics of the organisation's requisites and expectations have to be communicated effectively to be understood by every employee in their language perspective. Based on this premise, multinational companies take great efforts and make their management decisions percolated to the employees who are located at different countries, for its development.

Index Terms: Communication, Organisation, Paralanguage, Global environment, Goal, Organisational success, Management, Language barrier, Transnational

Objective: The objective of this paper is to elucidate as to why different languages are essential when it comes to organisational management.
\end{abstract}

\section{INTRODUCTION}

Languages are the most important element for written or verbal communication. Written communication is always a double edged sword. Since the communicator will not know in what mood the recipient would read, it becomes more difficult for the communicator who writes such written document. Also, there is a peril, whether the language that is being used in that communication would be understandable by the recipient in the same wavelength or meaning and context. Moreover, the nuances of every language are so varied in nature, even varied based on the geographical demography, it becomes more strenuous for the communicator to make the receiver comprehend in the same frequency that the communicator expects.

This article will analyse the above three aspects of why languages are the essential component for successful growth oriented management.

\section{THE ART OF COMMUNCATION}

The term 'Communication' infers the transmission of ideas, skills and knowledge between two or more persons through proper channels in an organisation. Everyone would agree, communication is the key for any organisation's function. Particularly, if the communication is effectively communicated, then the results will be positive. For this, the usage of the language should be in the proper perspective. In order to effectively use a language, one needs to have

Revised Manuscript Received on July 05, 2019.

Dr. M.G. Bhaskar, School of Management, SRM Institute of Science and Technology, Kattankulathur, Tamizhnadu, India. India .

knowledge not only about forming phrases but also make it comprehendible by the receiver.

Fortunately or unfortunately, every word in every language in general has more than one meaning. This is a great disadvantage for any communicator particularly from the management viewpoint. Usage of bombastic words or poetic words may not be understandable by the receiver. Similarly, usage of high-flown jargons may create miscommunication. This is the case even for those who understand the same language. In real time, the mood of the communicator and the recipient also will make or mar the content.

To explain this further, even simple sentences will carry different connotations.

1. 'Leave him not, hang him'.

2. 'Leave him, not hang him'.

The above example is of paramount importance in management communication and also the language used. There are certain times, in certain management communications; they purposely use certain words in an ambiguous manner to avoid assigning certain specific role and responsibilities. That is the reason, language and communication is a double edged sword.

This shows that language and its expressions are important along with the tone of authority when it comes to downward communications in any organisation. Similarly, the upward communication and its language should be appropriately written. In the present day scenario, communication within an organisation has become far more complex and varied. According to Myers and Myers, organisational communication is: "the central binding force that permits coordination among people and thus allows for organised behaviour" (qtd. in Ragusa 11). In order to tackle such issue internally, once can follow the following regulations for better understanding of internal communication in an organisation.

1. One should apply the KISS concept- 'Keep it short and simple'.

2. Use short phrases for easy understanding.

3. Ask straightforward questions to enable to clarify facts.

4. Use creativity to think of further questions.

5. Note down valuable points.

6. Exit with a good grasp of the outcome.

The blueprint for communication in general varies according to size of the organisations. While in a small size company, the messages can be easily conveyed and understood, whereas in companies of larger size, the communication must be more specific, planned and 
calculative as there will be many ranks within the organisation. In addition to it, the amount of work and the labour will be much more complex, that has to be addressed properly through proper mode of language in communication. Rogers and Rogers states: "the behaviour of individuals in organisations is best understood from a communication point of view" (qtd. in Ragusa 11).In organisations of larger capacity, the process of communication can be categorised into:

1. Interpersonal communication: Communication between two or a group of individuals.

2. Inter-organisational communication refers to the communication between parent vendor or $\mathrm{b} 2 \mathrm{~b}$.

3. Mass communication means communicating about a product or service to the end user or another organisational consumer.

4. Group level communication is for the team leaders, group heads and regional heads.

Effective communication within the organisation requires the following communication methods. They are:

1. A long term goal should be formulated.

2. Identification of plain ethics for the benefit of the organisation.

3. Explain simple set of objectives for internal communication policy.

4. Usage of detailed effective tactics.

5. Be logical in the messages conveyed.

The above mentioned principles and methodologies in corporate communication, even internationally, could be applied. To cite an example, the popular 'CitiBank' is in operation across the globe offering its valuable services of financial transaction that is very vital for any business, swiftly and efficiently. Even though 'CitiBank' services are the backbone for thousands of large multinational organisations across multilingual countries, 'CitiBank' has created a benchmark how efficiently the corporate communication should be even in multilingual scenario. 'CitiBank' has become a role-model not only for the service sector multinational organisations of giant magnitude; it is also a typical forerunner for very many manufacturing organisations too, with regard to language as a tool for effective communication management.

The same example can be cited even with regard to fulfilment of transnational legal compliances also, in-keeping with the various language barriers. Similarly, one can quote multiple examples not only by a non-Indian organisation but also by Indian multinationals like 'Tatas' who have operations in many countries.

Communication not only involves languages but also paralanguages. One should know the in-depth meaning of even a small gesticulation as it would become counterproductive in another ethnic environment. This may even result in cancellation of huge contracts in the highly competitive world business scenario. One cannot seek ignorance with regard to the paralanguage that is the most vital factor of corporate communication. Many instances have occurred in the past in the transnational critical negotiations because of lack of knowledge of this crucial paralanguage and its significance.

Yet another important communication hurdle to be known by every marketer dealing in many ethnic cultures is to know about the pauses between the words and the punctuation marks in written communication. Every comma or every semicolon or every hyphen should be used by knowing its full significance while conveying the semantic meaning that is very important with regard to managing the communication. Communication management is one of the strong pillars in the corporate world. Many of the large worldwide corporations have appointed and are always on the lookout for multi-language communication experts. They are the most sought after and very highly paid language professionals who creatively involve themselves in this complex specified area.

Exponents in this niche area who knows and understands and who can also interpret every word in any document for the benefit of their serving organisation commands very high respect amongst worldwide organisations. The art of communication is not merely a sentence formation in a particular language but has very rich and in-depth, effective long-term ramifications.

\section{CONCLUSION}

The world leaders and business magnets appoint their own personal language writing exponents to convey what they want, what they expect, on what obligations and in what parameters. This important portfolio is not generally being known to the common man or even organisations' doing multi-crore businesses. This proves how the language becomes a tool for effective communication management.

\section{REFERENCES}

1. Adair, John, Effective Communication: The Most Important Management Skill of All, revised edition., Pan Macmillan, 2011.

2. Adair, John, Effective Communication: The Most Important Management Skill of All, revised edition., Pan Macmillan, 2011.

3. Andersen, Peter B., Rodeny J.Clarke., et al. Coordination and Communication Using Signs: Studies in Organisational Semiotics. Springer Publication, 2002.

4. Blundel, Richard, Effective Business Communication: Principles and Practice for the Information Age. Prentice Hall, 1998.

5. Cushman, Donald P., and Chan, Dudley D. Jr., Fundamental of Organizational Communication. $8^{\text {th }}$ ed., Pearson, 2011.

6. Fielding, Michael, Effective Communication in Organisations. Juta \& Co., P Ltd, 2006.

7. Grant, Kevin., Hackney, Ray., et al., Strategic Information Systems Management, Cengage Learning EMEA, 2010.

8. C. J. Kaufman, Rocky Mountain Research Lab., Boulder, CO, private communication, May 1995.

9. Lane, Linda.L., Focus on Pronunciation: Principles and Practice for Effective Communication, Addison Wesley, 1993

10. Myers, Michele Tolela., and Myers, Gail. E., Managing by Communication: An Organisational Approach. McGraw-Hill, 1982.

11. Myrick, Martin C., Designing Effective Organisational Communications, Proquest Information \& Learning Company Publication, 2008

12. Perkins, P.S., The Art and Science of Communication: Tools for Effective Communication in the Workplace. Wiley, 2008.

13. Ragusa, Antonio, Internal Communication Management. Bookboon, 2011.

14. Sirbu, Anca. "The Significance of Language As A Tool Of Communication", Naval Academy Scientific Bulletin, vol. XVIII, no. $2,2015$. 